\title{
Patrimonio y habitabilidad contemporánea
}

\author{
José Ramón Moreno Pérez | Dpto. de Historia, Teoría y Composición Arquitectónicas, Universidad de Sevilla \\ Marta García de Casasola Gómez | Instituto Andaluz del Patrimonio Histórico
}

URL de la contribución <www.iaph.es/revistaph/index.php/revistaph/article/view/3913>

Imaginábamos, al interrogarnos sobre el objeto del patrimonio, una mesa, a la que en un arriesgado envite se convocaba a distintos jugadores. Su presentación consistía en una declaración sobre cuál eran sus intenciones y a partir de las mismas, un largo debate en el que fuera posible tramar una situación en que ese objeto se desvelara: un paréntesis en el que abordar lo instantáneo de su contemporaneidad. Esta imagen nos llevó a otra, utilizada por el escritor Paul Auster, en la que los convocados a la mesa actúan como si fueran espejos que se reflejan unos a otros. A partir de ahí, su utilidad era manifiesta para el objetivo que pretendíamos alcanzar, tan sólo con disponer ese objeto patrimonial en medio: confiando que los reflejos en esos espejos-jugadores fueran capaces de iluminar la forma y naturaleza de aquello que se reflejaba. Palabra e imagen como vehículos para construir un enclave del patrimonio contemporáneo, en la época del espectáculo.

Días después la partida o los reflejos se han materializado y, a modo de corresponsales, realizamos esta crónica con el ánimo de que los lances del debate o las imágenes en los espejos no terminen de producirse, tan necesitados estamos de que unos y de otros se interrelacionen.

Adoptando la estrategia de la araña, que va con sus hilos de un punto a otro del medio en que vive, para tejer una red de reenvíos entre posiciones alejadas, que permitan visualizar que algo existe en medio, algo que supera lo mantenido por cada una de esas posiciones, nos atrevemos a lanzar cuatro hilos maestros que pudieran arracimar opiniones diferenciadas en un proceso extendido a ese vacío central de la mesa de convocatoria:

El primero: que el patrimonio -cosa, objeto, símbolo, lugar, imagen, simbionte...- permite, sobre la base de su materialidad cultural, iluminar el tránsito antropotécnico de la civilización humana y, por ello, actúa como un compás de movimiento entre técnica y cultura o producción y significación o sumersión e inmersión, un lugar simbólico para la construcción de una co-habitabilidad humana.

Los espejos o jugadores que lo reflejan o lo juegan serían tan diversos como las opiniones presentes en la convocatoria, que se instalan diferenciadamente: en la lógica del archivo, en la tecnología o en el reciclaje de la materialidad: llamando, unas y otras, a la resiliencia, a la habitabilidad de los centros históricos, a la política como proyecto de identidad híbrida, a la temporalidad conflictiva de lo contemporáneo, al cepo del consumo, para proponer una discursividad que abra su configuración actual a nuevos entendimientos, a nuevos modos de vida, a la problemática de su pervivencia en la época de lo "monstruoso".

El segundo: cada jugador o espejo se instala en una determinada posición dentro de una mesa que pertenece o está rodeada de entornos que la circundan sucesiva y activamente y, cuyo horizonte máximo, puede llamarse globalización o coinmunidad. De esta manera, sus aportaciones transdiciplinares se posicionan como alternativas frente a lo político establecido y lo teórico convenido. En todos ellas, subyace un compromiso y una apuesta potente por la calidad de vida, por la ecología de nuestros entornos: sea a partir del entendimiento del patrimonio como sistema de inmunidad simbólico, sea como componente de un entendimiento democrático de las políticas culturales.

Sus reivindicaciones alcanzan al aprendizaje, incluso a sus proyectos docentes y permite el "extrañamiento" como mecanismo de aproximación a algo siempre desconocido para hacerlo visible y recuperar la libertad. 


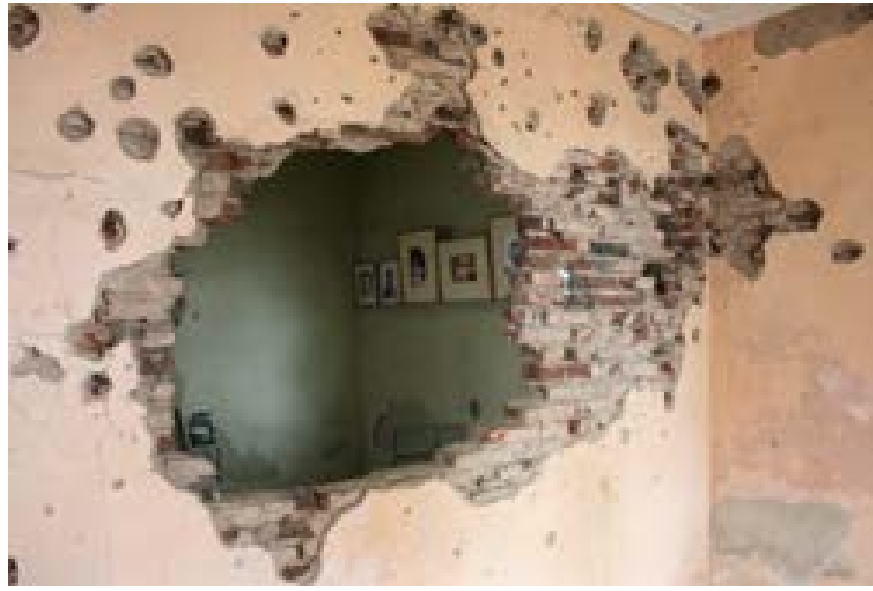

Casa Mariani-Teruggi, La Plata (Argentina). Ana Ottavianelli, Fernando Gandolfi, arquitectos

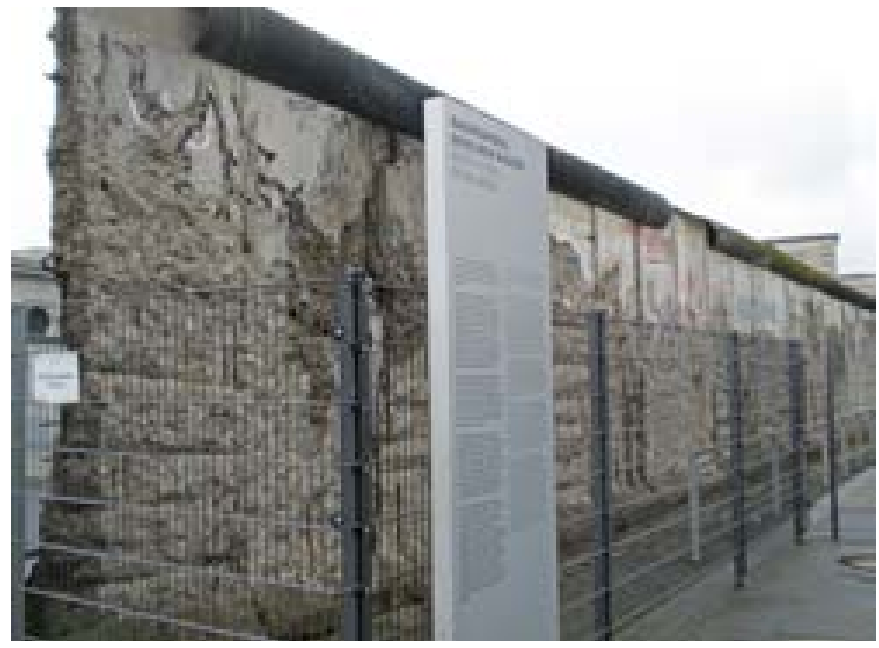

Muro de Berlín musealizado | foto Amanda Slater

El tercero: todos ellos vienen al juego o al reflejo, contando con un bagaje y unas claves de entendimiento resultados de su pertenencia a una red, una de esas redes que se extienden por los territorios de la globalidad; o diferenciadamente, en el cobijo o acantonamiento en uno de sus nudos, sabiendo que sus discursos deben superar el vacío de la mesa o el vacío del círculo del objeto e interaccionarse con los otros jugadores, pues sólo así será posible que el juego conforme un objeto nuevo o lo que de ello resulta; al tiempo que se constituye una comunidad que lo acoja;

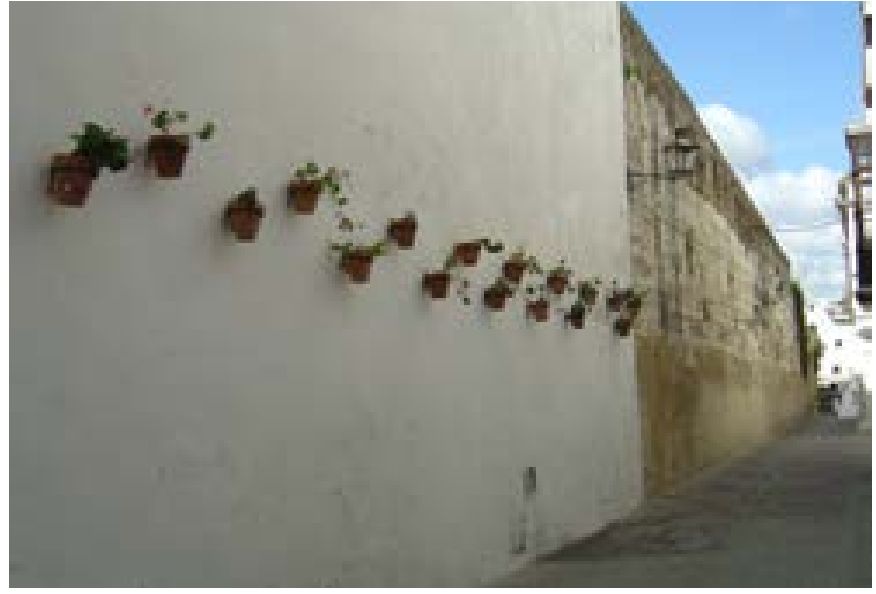

Arcos de la Frontera, Cádiz | fotos Marta García de Casasola Gómez

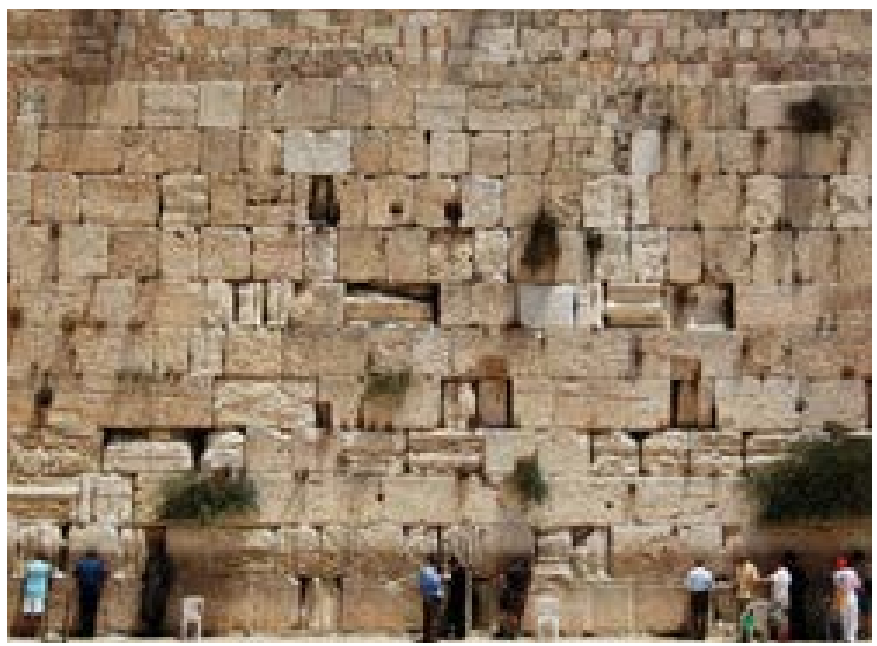

Muro de las Lamentaciones, Jerusalén | foto bachmont

la suya es una apuesta esperanzada, con "muchas pretensiones".

El cuarto: sus palabras y reflejos hablan del combate en el que parte del patrimonio se halla enfrascado, para lograr abrir un paréntesis entre la democracia biopolítica y las comunidades terribles, que incorporen a su contemporaneidad un pasado siempre abierto. Sus tácticas y maniobras son múltiples y complementarias, aparecen: en la determinación de la tecnología -en su virtualidad o en el desvelamiento de la materialidad-; en la caja 


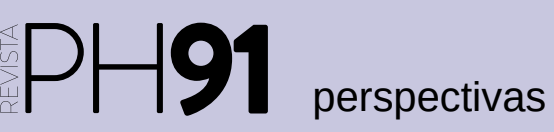

a debate Visiones patrimoniales para definir el objeto del siglo

| coordinan José Ramón Moreno Pérez, Marta García de Casasola Gómez

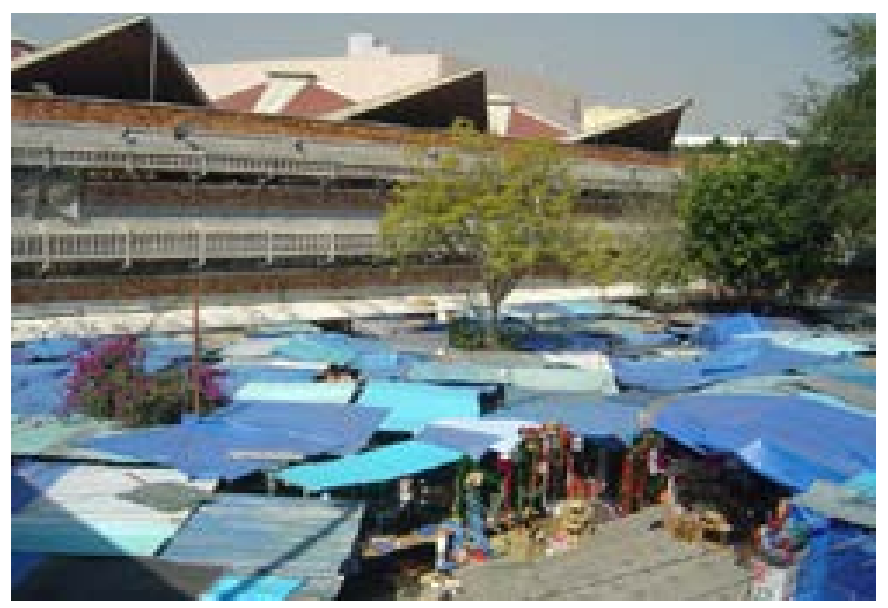

Mercado de San Juan de Dios, Guadalajara (México)

de escalas que hace saltar la organicidad dimensional del patrimonio, llevándolo a una revisión dimensional de sus enclaves; en la inmunidad de su identidad simbólica, amenazada por la sincronización de los lenguajes de la globalización; en la resiliencia abierta y nunca acabada -en el "trato con las cosas cubiertas por las cenizas del tiempo"- del archivo o de la tutela; en los lugares que -como partes del cuerpo- bajo su nombre se protegen: territorio, ciudad, barrio, monumento, ruina, paisaje...

Y resulta de todo ello, que ahora existe "en medio", una comunidad de opinión que debería ser-como en el final del texto de Carrera- una invitación a su materialización social, a su constitución como práctica política, a su capacidad para soportar otra habitabilidad; es en ellas donde se guardan verdaderamente el objeto patrimonial por el que nos preguntamos, cuya configuración ya no podrá ser determinada formalmente por las instituciones, las cartas o las constituciones, pues su estructuración está disuelta en lo colaborativo, en su pertenencia cambiante a una cultura emergente.

De esa continuidad desplegada en diversas facetas de la acción cultural nos hablan otros: a partir de la necesidad de introducir una atención especial a determinados objetos - ¿patrimoniales?- que, sumergidos en el sistema del consumo, ocultan sus valores tras la máscara de la plusvalía, sea esta mediática, adquisitiva, política,

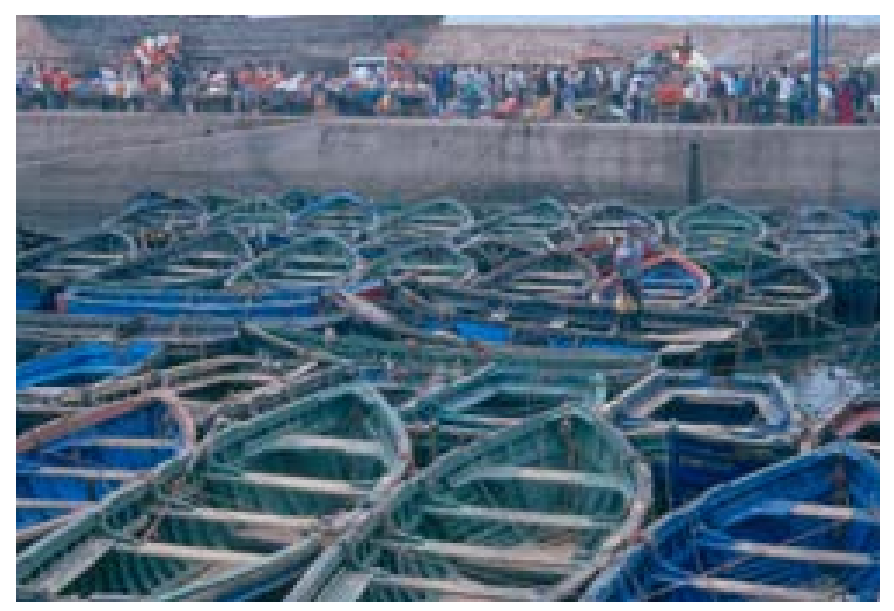

Esauira (Marruecos) | fotos Marta García de Casasola Gómez

estética o identitaria; construyen mediante un aprendizaje que corta transversalmente cualquier organización disciplinaria, un alojo para determinados proyectos alternativos: de docencia o divulgación.

$\mathrm{O}$, de otra manera, construyen redes de actores que se ejercitan sobre la acción patrimonial de manera alternativa. Una ejercitación que contiene posiciones, estructuras, escalas u organizaciones muy distintas a las que viene codificada por el sistema patrimonial, que defiende valores y comportamientos, éticas y responsabilidades alternativas, que usa de manera táctica una "inteligencia general", tan poco reconocida, porque tan sólo es considerada como práctica del mimo o la descarga.

$\mathrm{Si}$, como afirman esas palabras y reflejos, este camino lleva a otra razón política, que basada en lo participativo, actúa estratégicamente infiltrándose en lo institucional, sin ser capaz aún de formularse como un proyecto patrimonial alternativo; ello debería hacernos conscientes de lo fuerte que son las determinaciones de las democracias biopolíticas en este campo y de una inevitable labor de deconstrucción de su axiomática.

Soportada por una nueva habla patrimonial, que desafía los tesauros, que es habla sesgada respecto a las palabras icónicas de lo institucional, que hibrida campos de conocimiento para poder alcanzar una expresión 


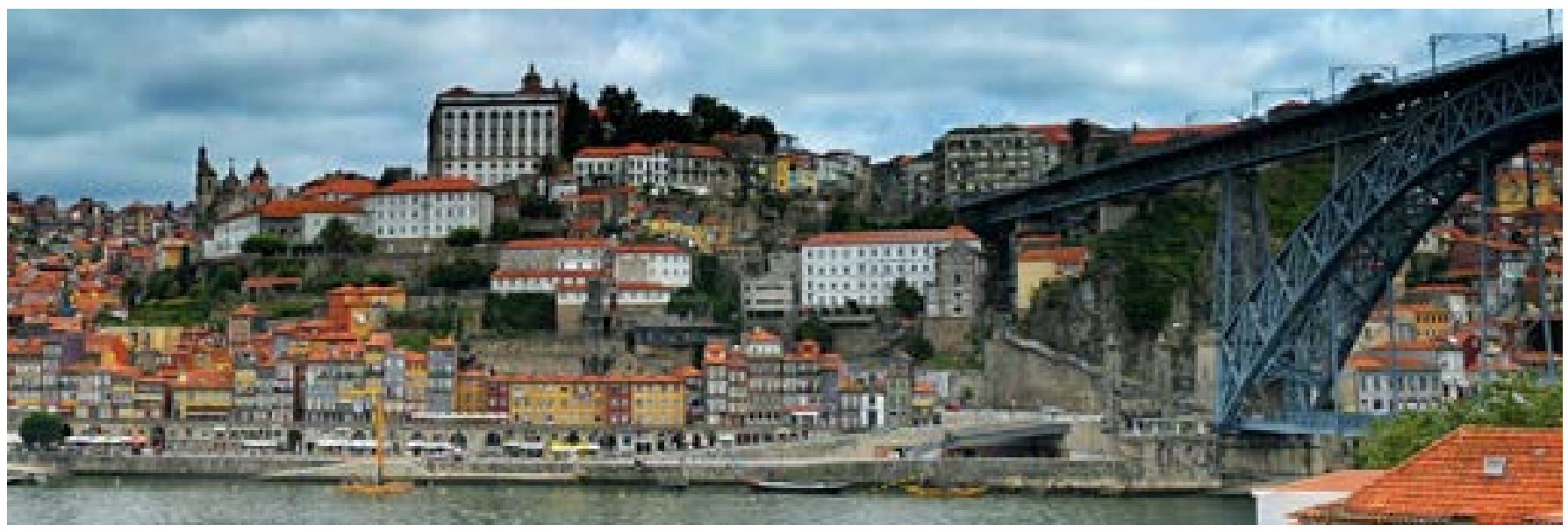

Centro histórico de Oporto | foto jesuscm (http://jesuscm.com/)

identitaria o informacional: patrimonio como indicio temporal -recabando una cultura histórica alternativa, en la que el paradigma del espía o los espacios de montaje de Warburg, pasan a ocupar el primer plano-; patrimonio como práctica saludable, como equilibrio logrado entre medio y habitabilidad -poniendo en contacto dos de los emblemas de la cultura contemporánea-; patrimonio informado -encontrando para una realidad irrealizada una capa de intermediación entre la nube y la cotidianeidad-; patrimonio dinámico -como umbral de sucesiones-; patrimonio como proceso de desacralización -avanzando así en la deconstrucción olvidada o pospuesta de los valores de trascendencia, heredados del antiguo régimen-; patrimonio como volubilidad -oponiendo su impacto máximo y su obsolescencia inmediata a la práctica del reciclaje-; incorporándose así a una práctica cultural contemporánea, que partiendo del diagnóstico de la expropiación del lenguaje por los medios, se posiciona en ese vacío para inventar un lenguaje propio. Aquí también surge otro componente fundamental de una emergente política patrimonial que, incrustada en los marcos institucionales, en silencio, sin acceder a lo noticiable, "lanza al mar negro una galleta de colores". Ese despliegue de reflejos y palabras, transita por una doble dirección: de lo cultural al patrimonio y de este al entorno, que ahora puede ser abordado -como apunta Choay- a partir de un modelo de intervención alternativo, que permite la transferencia entre instancias ina- parentes, que de esta manera protagonizan desde su desvelamiento nuevos relatos y nuevas prácticas. Actuemos como mediadores desvelando/construyendo soportes en los que la vida tenga lugar, de manera que conocimiento y vida establecen así una nueva alianza, en la que el patrimonio, ese objeto del siglo -del que nos hablaba G. Wajcman-ya no deberá ser más moneda de cambio para dispositivos de dominación, sino un componente transversal de comunidades que ya no sean terribles.

Situada al final de un fin, esta convocatoria -así lo muestran sus asistentes- tiene la virtud de radiografiar una situación compleja, en la que se debate -insuficientemente- sobre un modelo patrimonial, que tuvo como objeto de atención la construcción de una identidad territorial, en ello reside sus logros e insuficiencias, de manera directa o tangencial, todas las colaboraciones apuntan a ello. Desplazando el centro de atención a aspectos -aparentemente- menores o marginales, que poco a poco apuntan mucho más allá de lo creído, convirtiéndose en facetas constitutivas de algo que esperanzadamente observamos como un modelo patrimonial. 